\title{
Smoking guns and volcanic ash: the importance of sparse tephras in Greenland ice cores
}

\author{
Gill Plunkett, ${ }^{1}$ Michael Sigl, ${ }^{2}$ Jonathan R. Pilcher, ${ }^{1}$ Joseph R. McConnell, ${ }^{3}$ Nathan Chellman, ${ }^{3}$ J.P. Steffensen ${ }^{4}$ \& \\ Ulf Büntgen ${ }^{5,6,7,8}$
}

${ }^{1}$ Archaeology and Palaeoecology, School of Natural and Built Environment, Queen's University Belfast, Northern Ireland, UK;

${ }^{2}$ Climate and Environmental Physics, Physics Institute \& Oeschger Centre for Climate Change Research, University of Bern, Bern, Switzerland;

${ }^{3}$ Division of Hydrological Sciences, Desert Research Institute, Reno, NV, USA;

${ }^{4}$ Centre for Ice and Climate, University of Copenhagen, Copenhagen, Denmark;

${ }^{5}$ Department of Geography, University of Cambridge, Cambridge, UK;

${ }^{\circ}$ Swiss Federal Research Institute WSL, Birmensdorf, Switzerland;

${ }^{7} \mathrm{Global}$ Change Research Centre (CzechGlobe), Brno, Czech Republic;

${ }^{8}$ Department of Geography, Faculty of Science, Masaryk University, Brno, Czech Republic

\begin{abstract}
Volcanic ash (fine-grained tephra) within Greenland ice cores can complement the understanding of past volcanism and its environmental and societal impacts. The presence of ash in sparse concentrations in the ice raises questions about whether such material represents primary ashfall in Greenland or resuspended (remobilized) material from continental areas. In this article, we investigate this issue by examining tephra content in quasi-annual samples from two Greenland ice cores during a period of ca. 20 years and considering their relationships with sulphur and particulate data from the same cores. We focus on the interval 815-835 CE as it encompasses a phase (818-822 CE) of heightened volcanogenic sulphur previously ascribed to an eruption of Katla, Iceland. We find that tephra is a frequent but not continuous feature within the ice, unlike similarly sized particulate matter. A solitary ash shard whose major element geochemistry is consistent with Katla corroborates the attribution of the $822 \pm \mathrm{CE}$ sulphur peak to this source, clearly showing that a single shard can signify primary ashfall. Other tephras are present in similarly low abundances, but their geochemistries are less certainly attributable to specific sources. Although these tephra shards tend to coincide with elevated sulphur and fine $(<10 \mu \mathrm{m})$ particulates, they are not associated with increased coarse $(>10 \mu \mathrm{m})$ particle concentrations that might be expected if the shards had been transported by dust storms. We conclude that the sparse shards derive from primary ashfall, and we argue that low tephra concentrations should not be dismissed as insignificant.
\end{abstract}

To access the supplementary material, please visit the article landing page

\section{Keywords}

Primary ashfall; resuspended volcanic ash; volcanic eruptions; Katla; dust storms; tephrochronology

\section{Correspondence}

Gill Plunkett, Archaeology and Palaeoecology, School of Natural and Built Environment, Queen's University Belfast, Belfast BT7 1NN, Northern Ireland, UK. E-mail: g.plunkett@qub.ac.uk.

\section{Abbreviations}

CE: Christian Era

GRIP: Greenland Ice Core Project Ky: thousands of years NEEM: North Greenland Eemian Ice Drilling research project

\section{Introduction}

In recent years, evidence for past volcanic impacts on climate variation and societal transformation has increasingly been posited (Esper et al. 2013; Sigl et al. 2015; Stoffel et al. 2015; Büntgen et al. 2016). The climate effectiveness of eruptions stems from the capacity of material injected into the stratosphere, particularly sulphur-containing gases that convert to sulphate aerosols, to deflect incoming solar radiation over the course of weeks to years, triggering surface cooling (Robock 2000), although ash particles may offset the cooling in some instances (Flanner et al. 2014). Volcanic eruptions vary greatly in their magnitude, duration and type of emission, and their latitudinal location is also a significant factor in the potential extent of their atmospheric 
impact (Toohey et al. 2019). As volcanic eruptions occur globally on a continual basis, including several that penetrate stratospheric levels each decade, it remains to be established which types of events pose the greatest risk to the climate system.

The understanding of past volcanic impacts hinges substantially on the polar ice core records that present an extended history of volcanic activity through their chemistry, most notably of eruptions that emitted sufficient aerosols to have potentially impacted the Earth's radiative balance (Hammer et al. 1980; Zielinski et al. 1994; Sigl et al. 2013). For the Late Holocene, ice cores offer a level of chronological precision that enables their records to be reconciled with historical events, allowing climate perturbations and any ensuing societal impacts to be evaluated (Sigl et al. 2015; Büntgen et al. 2016). Identifying the source eruption is key to deciphering the volcanic processes that impact the climate system. For example, atmospheric loading of volcanic aerosols is best reconstructed if the latitude, other eruption parameters (e.g., plume height, eruption style) and season are known. However, in many regions, observational records of eruptions began only in recent centuries, and volcanic histories remain very poorly resolved in many regions (Siebert et al. 2011). Furthermore, secure attribution of volcanic signals to specific eruptions can only be achieved through the analysis of associated volcanic ash (fine-grained tephra) particles whose glass geochemical composition may point to the source eruption, volcano or volcanic region.

Transport of volcanic ash to polar regions is constrained by several factors, however, not least injection height, meteorological conditions at the time of the eruption over both the source volcano and the deposition site, and general atmospheric circulation patterns. Given these limitations, it is perhaps not surprising that concentrations of ash particles large enough (usually $>20 \mu \mathrm{m}$ ) to be geochemically typed by using standard tephra-analytical techniques in polar ice are frequently low (Iverson et al. 2017). For Late Holocene Greenland ice, Coulter et al. (2012) examined multi-annual samples with as few as one tephra shard identifiable by using light microscopy, while other studies have been limited to analysing particles $<10 \mu \mathrm{m}$ by using sub-optimal techniques for geochemical characterization (Palais et al. 1992; Zielinski et al. 1997; Barbante et al. 2013). Such a very fine-grained material might not be recognizable as volcanic glass by using standard optical microscopy for routine tephra screening.

A major concern relating to sparse cryptotephras in polar ice is whether they represent primary ashfall or reworked (secondary) material. Prevailing wind patterns, the high latitude and altitude of the ice core sampling locations and the specific environmental conditions required to resuspend ash from older deposits are amongst the leading factors that mitigate the incorporation of reworked tephra into the ice. Nevertheless, it is conceivable that strong dust storms could transport resuspended sediment, including tephra, over long distances to polar areas. Aeolian resuspension of ash is especially likely in areas where pedogenesis and stabilization by vegetation cover are retarded or absent, namely in very cold or very arid regions. In the Valley of the Ten Thousand Smokes, Alaska, for instance, tephra beds from the 1912 Novarupta eruption remain exposed as climate and topography combine to hinder the establishment of pioneering vegetation (Hildreth \& Fierstein 2012). Under certain wind conditions, ash from these beds can be resuspended and elevated as much as $3 \mathrm{~km}$ into the atmosphere, equivalent to a plume from a Vulcanian-style eruption and sufficient to enable ash to be dispersed over several thousand kilometres (Hadley et al. 2004). How then do we differentiate primary ashfall from dust deposition events incorporating remobilized tephra? Although reworked glass can sometimes be evidenced by rounded edges, corrosion or altered major element geochemistries (Lowe 2011), these indices may depend upon factors such as the length of time a tephra has been exposed to weathering prior to remobilization, or transport mechanisms. Low analytical totals in geochemical analyses can also result from post-deposition hydration of the glass under exposed conditions, although other factors contributing to low totals include thin glass walls and instrumental error (Froggatt 1992; Hunt \& Hill 1993).

In terms of the potential source area of reworked volcanic material reaching Greenland, we might reasonably assume a correlation with the sources of fine particulate matter in the ice that regularly reaches polar locations. Strontium ( $\mathrm{Sr}$ ) and neodymium (Nd) isotope analyses of $<5 \mu \mathrm{m}$ particles in high-altitude Greenland ice cores indicate a predominantly east Asian origin (Bory et al. 2002; Bory et al. 2003), although others propose that a north African source may be underestimated in these studies (Tanaka \& Chiba 2006; Lupker et al. 2010). Winter atmospheric circulation over both the Greenland NEEM and Tunu ice-core drilling sites is dominated by the polar vortex. In spring to summer, air masses over both sites originate mainly from the west, but both sites are also influenced by air masses from the North Atlantic, arriving at NEEM from the south and at Tunu from the north-east and south-east (Steen-Larsen et al. 2011; Maselli et al. 2017). With the exception of Iceland and the Jan Mayen islands (whose tephras are geochemically well-characterized), however, these regions do not feature unconsolidated ash beds from which reworked tephra could derive. In Iceland, dust remobilization also occurs predominantly 
in spring and early summer and, from southern Iceland at least, dust is mainly transported southwards (Prospero et al. 2012). On balance, it seems that the most probable sources of reworked tephra that might reach Greenland will lie to the west.

How meaningful, therefore, are sparse tephra particles recorded in the ice? Do occasional shards merely reflect a background signal of remobilized ash particles or can they represent primary ashfall? To address these questions, we consider a ca. 20-year interval of ice from two northern Greenland ice cores-NEEM-2011-S1 and TUNU2013 (Fig. 1) - to investigate the frequency and origin of volcanic ash in the records, and their relationship to other volcanogenic proxies.

\section{Materials and methods}

Sulphur concentrations from the TUNU2013 and NEEM-2010-S1 Greenland ice cores have previously been reported (Sigl et al. 2013; Sigl et al. 2015). For the TUNU2013 core, fine particulate matter was measured for two fractions $(2.6-4.5 \mu \mathrm{m}, 4.5-9.5 \mu \mathrm{m})$ during continuous flow analysis of an adjacent parallel melter stick from the core (Ruth et al. 2003; Sigl et al. 2013; Jensen et al. 2014). We examined sections of ice from both cores spanning the period from about $815 \mathrm{CE}$ to about $835 \mathrm{CE}$, encompassing an extended volcanogenic acid signal between 818 and 822 CE (Büntgen et al. 2017). Constrained at the $774 \mathrm{CE}$ cosmogenic event (Miyake et al. 2012), both chronologies have an error of \pm 1 year in this interval (Sigl et al. 2015). In total, $4.42 \mathrm{~m}$ of ice from NEEM-2010-S 1 and $2.01 \mathrm{~m}$ from TUNU2013 were subsampled at approximately annual resolution, comprising 40 individual samples. Samples were cut from archived ice at the Desert Research Institute, Reno, Nevada, by using a bandsaw and transferred to sterile Nalgene bottles. These samples comprise surface areas mainly between 15 and $20 \mathrm{~cm}^{2}$, greater than the area sampled in previous studies (e.g., Coulter et al. 2012); coupled with the high-latitude, high-elevation locations of the coring sites, they present only a small opportunity to capture remnants of sparse or fleeting ash clouds. In addition, a sulphur peak at $822 \mathrm{CE}$ in TUNU2013 was subsequently resampled with respect to a prominent peak in particulate matter; for this event, fine resolution (sub-annual) samples were collected immediately before, across and after the particle peak, bringing the total number of samples examined to 43 .

Samples were shipped to Queen's University Belfast, where they were prepared by centrifuging the meltwater to concentrate the particulates, which were then pipetted onto pre-ground glass slides in a laminar flow cupboard and covered in Buehler ExopyCure2 resin. Each sample was assigned a unique identifier code (prefixed QUB-). Slides were scanned at $\times 100$ magnification on a light microscope, and tephra particles were identified with the aid of cross-polarized light. The number of particles $>10 \mu \mathrm{m}$ within each sample was also counted and converted to concentrations to quantify coarse material flux within the ice cores. For samples containing tephra, thin sections were prepared by

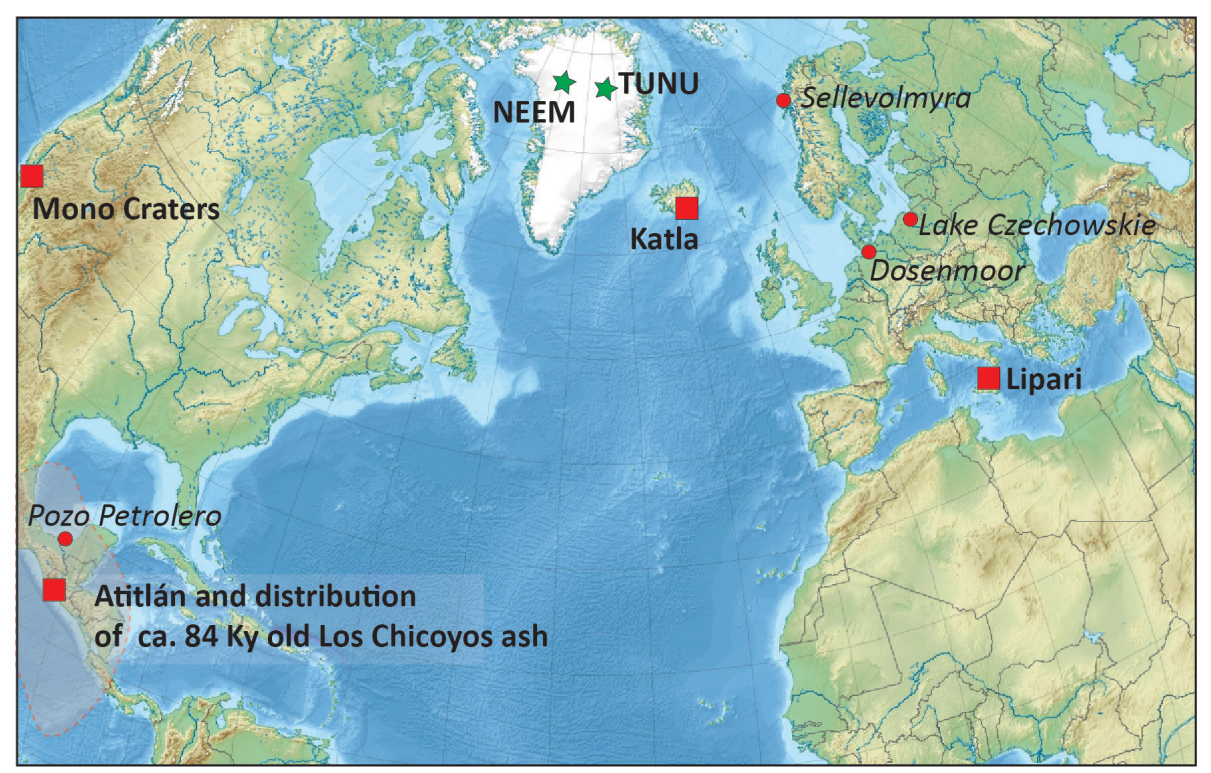

Fig. 1 Location of NEEM and TUNU2013 coring sites (stars) with respect to volcanic sources (squares) referred to in the text. The locations of sites in which cryptotephra of similar major element geochemical glass composition to QUB-1880 are also indicated (circles; see Plunkett \& Pilcher 2018 for a discussion of these tephras). 
grinding and polishing the slides until the surfaces of tephra shards were freshly exposed. Major element geochemical composition of the glass shards was determined by using integrated electron and wavelength dispersive spectrometry on a JEOL FEGSEM 6500F at Queen's University Belfast following Coulter et al. (2012). Secondary glass standards were analysed at the start and end of each session and between samples to evaluate analytical precision. All data were normalized to facilitate comparison with published data, and are reported, along with secondary glass standard data, in the Supplementary Data Set.

\section{Results}

Figure 2 shows the positions of the tephra samples relative to the available sulphur and particle concentrations in the NEEM-2011-S1 and TUNU2013 ice cores. The extended period of heightened sulphur volcanism evident in the NEEM-2011-S1 core between 818 and 822 CE (Büntgen et al. 2017) is also visible in TUNU2013. The TUNU2013 record contains greater inter-annual variability, however, potentially owing to (1) the coring site's closer proximity to Iceland, (2) the site's lower elevation that places it closer to tropospheric sulphur emission sources and (3) the lower snow accumulation rate, which allows for enhanced surface snow mixing. Fluctuations in the TUNU2013 fine $(<10 \mu \mathrm{m})$ particle fractions follow neither an annual nor a seasonal pattern. Both fractions show close correspondence with each other, with elevated levels at $814,817,822,823,825$ and $830 \mathrm{CE}$, with smaller peaks at $815,816,819,821,826,831$ and $832 \mathrm{CE}$. Visual examination of the samples under a light microscope showed the prominent peak at ca. 830 CE (QUB$1886)$ to relate to mineral dust. The smaller peaks at ca. 826 CE (QUB-1883), 831 (QUB-1888) and 832 CE (QUB1889) also contained mineral dust and variously included occasional examples of charcoal, fungal spores and diatoms. Coarse particles $(>10 \mu \mathrm{m})$ were present in all samples, but their concentrations were an order of magnitude greater in the TUNU2013 core (Supplementary Data Set). Notable increases in coarse particles occur in the NEEM2011-S 1 core at 828-9 (QUB-1847) and 835-6 CE (QUB1853), and in TUNU2013 at 814 (QUB-1870) and 826-7 CE (QUB-1883); only the last-mentioned peak coincides with elevated sulphur levels. QUB-1878, dating to 821-2 $\mathrm{CE}$, contained a large number of poorly preserved sponge spicules and diatoms, as did the overlapping sample QUB1974; the presence of such material implies the transport of marine water to the sampling site.

Only five of the 43 quasi-annual samples yielded unambiguous tephra particles, ranging from one to five shards per sample (Supplementary Data Set;
Supplementary Figs. S1-S6); in some of these, additional potential shards were present but were too small to enable certain identifications. A probable glass shard was recorded in one other sample (QUB-1841; Supplementary Fig. S2), but its diminutive size prohibited geochemical analysis. Although it is now possible on certain

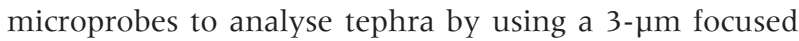
beam (Hayward 2012), it remains a major challenge to expose a large enough surface area of glass in thin section without destabilizing the resin or polishing away the shard, especially if shards have a platey (i.e., thin) morphology. Possible tephra shards were also present in QUB-1870, but none of the analysed targets proved to be glass; this sample also contained the highest concentration of coarse particles in all of the ice examined in this study. As a test of the reliability of the analytical data obtained from the very sparse shards and to ensure that results were not skewed by the presence of mineral inclusions, multiple analyses from each shard were obtained where particle size permitted.

Analytical totals frequently fell below the normally accepted threshold of $95 \mathrm{wt} \%$ proposed by Hunt \& Hill (1993), albeit above ca. 90 wt\% deemed acceptable by Froggatt (1992). We have found this to be a frequent challenge when working with small particles as epoxy resin is entrapped during analysis, demonstrated by elevated $\mathrm{Cl}$ (Coulter et al. 2012). In some instances reported here, we attribute low totals at least in part to instrumental settings, noting lower than usual totals for the secondary glass standards at the time of analysis (see Supplementary Data Set).

\section{QUB-1835, 815 CE}

A single bubble-walled shard of colourless glass in NEEM2011-S1 yielded three analyses, but the composition of the initial analysis is not replicated by the subsequent two. Geochemical heterogeneity and low analytical totals $(<95 \mathrm{wt} \%)$ highlight a need for caution in the interpretation of the data. However, the glass showed no physical signs of weathering, and post-analysis examination shows burning beyond the edges of the shard (Supplementary Fig. S1), which will have contributed to low totals, as well as Cl entrapment. All things considered, therefore, we attribute the low totals to problematic analyses rather than hydration. An attempt to characterize the trace element composition of the QUB-1835 shard by using laser ablation inductively coupled plasma mass spectrometry proved unsuccessful because of the return of a low signal, reflecting the limited glass available for analysis. In NEEM-201 1-S 1 at this time, sulphur remains at background levels.

In our database, the major element composition of the first analysis most closely matches that of Lipari, Italy 
(Supplementary Fig. S7), the Monte Pilato eruptive event of which has been dated to $776+100 /-90$ CE (Keller, cited by Lucchi et al. 2007) and is therefore within the same timeframe. The subsequent analyses are not, however, consistent with this source but are instead similar to some material from the South Mono eruption of Mono Craters, California, dated to 594-648 CE (Bursik et al. 2014). Interestingly, Bursik et al. (2014) have posited a remobilization event following a fire ca. 200 years after the South Mono eruption. However, we observe no obvious
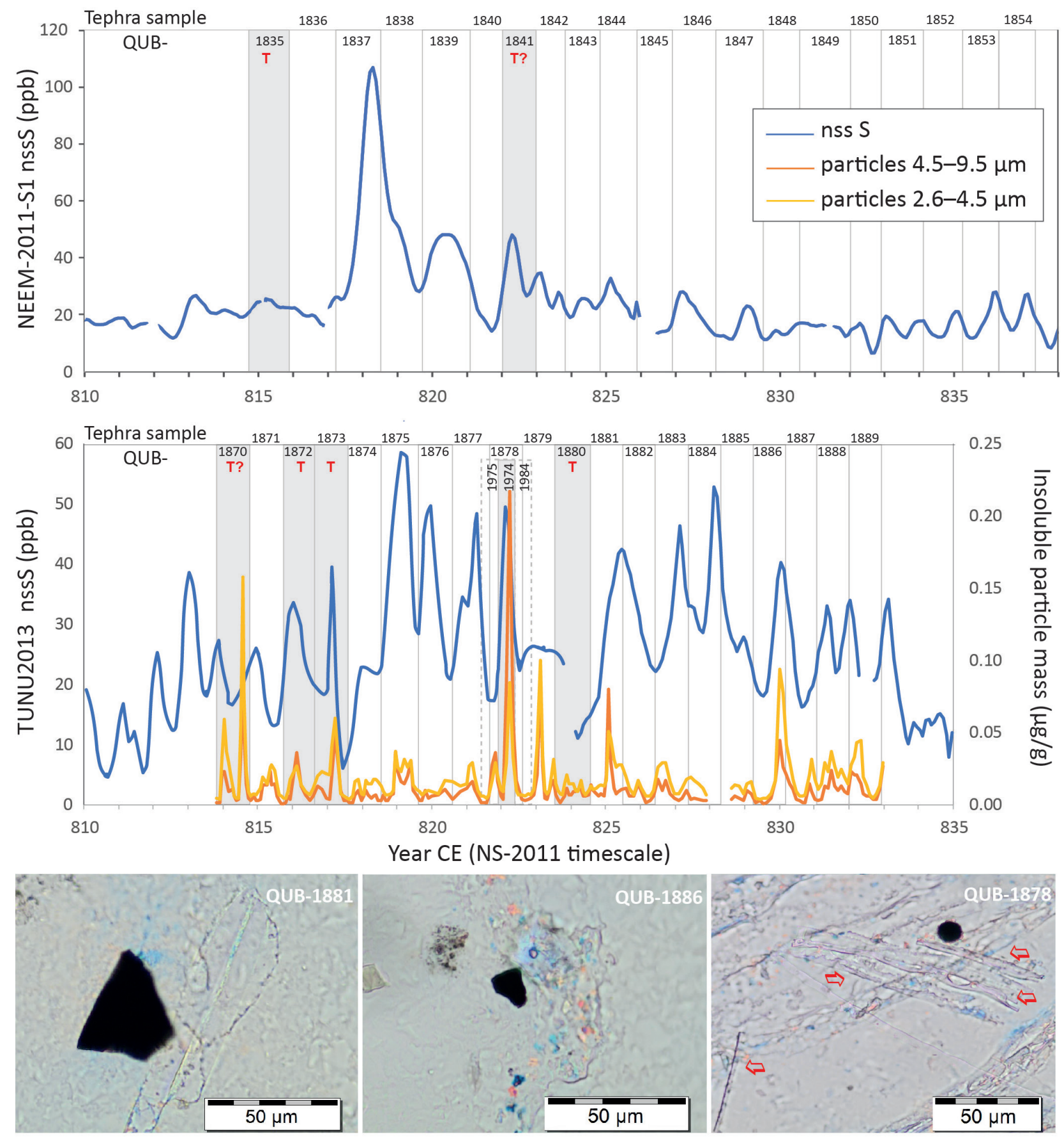

Fig. 2 Positions of tephra samples from the NEEM-2011-S1 and TUNU2013 ice cores in relation to their respective non-sea salt sulphur (nssS) records, and the insoluble particle record from TUNU2013. T or T? indicates the presence of tephra or possible tephra. Examples of non-tephra particles are shown below (QUB-1881: charcoal and diatom; QUB-1886: charcoal and fine dust; QUB-1878: fine dust, biogenic silica). 
increases in either coarse particle content or charcoal that might suggest a dust deposition event, particularly one associated with a fire. No tephra was identified in the corresponding levels in TUNU2013.

All in all, given the questionable quality of the data, it is not possible to propose correlatives for this tephra, and further sampling of ice of this age is warranted. The geochemical heterogeneity of the shard is possibly indicative of secondary deposition of weathered glass, but in view of the shard size $(>40 \mu \mathrm{m})$, the absence of visible signs of weathering and the lack of other material in the sample that would point to a dust event (e.g., charcoal, pollen, coarse-grained minerals), we conclude that QUB-1835 is likely to be the result of primary airfall.

\section{QUB-1872, 816 CE}

Three analyses were obtained from a colourless, platey shard in TUNU2013. The shard is characterized by a very distinctive high $\mathrm{SiO}_{2}$ and very low $\mathrm{FeO}_{\text {total }}$ and $\mathrm{CaO}$ content. Analytical totals were consistently low, but the data indicate a homogenous chemistry across the shard. We have been unable to identify a possible source for this tephra, but similar tephras of Pliocene to Pleistocene age have been reported from marine cores from the north-western Pacific (Cao et al. 1995), suggesting a potential derivation from the Kamchatkan/Kurile region. Four additional tephra-like particles measuring ca. 10-20 $\mu \mathrm{m}$ were present but were too small to analyse on our instrument. A range of similarly sized minerals, including feldspars, were present but not notably abundant. The TUNU2013 sulphur and particle records are slightly elevated in early $816 \mathrm{CE}$. The potential source region (i.e., upwind of Greenland) for the analysed shard increases the likelihood that this material could be reworked, yet the homogeneous glass geochemistry and the simultaneous increase, albeit modest, in sulphur are consistent with primary deposition following an eruption.

\section{QUB-1873, 817 CE}

A single shard of brown, cuspate glass produced three consistent analyses that indicate a trachydacitic composition. No certain correlatives were identified for this tephra, but the chemistry is similar to the ca. 80-Ky-old NEEM2049.3 identified in Greenland ice and attributed to the Eastern Aleutian Arc (Bourne et al. 2016; Supplementary Fig. S8). It also bears some similarities to trachydactic glass from Shiveluch (Ponomareva et al. 2015; Ponomareva et al. 2017), although such glass has not been reported from this time interval. Some smaller glass particles $(<20 \mu \mathrm{m})$ were also noted, and other large particles were present in below-average concentrations. The sample's position in
TUNU2013 coincides with small peaks in sulphur and fine particles in early $817 \mathrm{CE}$. On the basis of the consistent analyses and association with volcanogenic sulphur, we propose that this particle is from primary ashfall.

\section{QUB-1974, 822 CE}

Only one analysis was feasible on the isolated light brown, cuspate shard recorded in this TUNU2013 sample. Despite a low analytical total, the distinctive geochemistry can reliably be attributed to Katla, Iceland (Supplementary Fig. S9). This sample is directly associated with major fine particle and sulphur peaks in early $822 \mathrm{CE}$, but coarse particles were not notably abundant in this or the overlapping sample QUB-1878. In view of the shard's unambiguous geochemistry and its direct association with a significant sulphur peak, we conclude that the shard is undoubtedly from primary ashfall.

\section{QUB-1880, 824 CE}

Of the four certain glass shards identified in this TUNU2013 sample, analyses were obtained from three. All three shards are rhyolitic and characterized by low $\mathrm{CaO}(<0.9 \mathrm{wt} \%)$ and high $\mathrm{K}_{2} \mathrm{O}(>4 \mathrm{wt} \%)$. One shard yielded three slightly dissimilar analyses, all comparatively enriched with $\mathrm{Al}_{2} \mathrm{O}_{3^{\prime}} \mathrm{FeO}_{\text {total }}$ and $\mathrm{TiO}_{2^{\prime}}$ pointing to the entrapment of a large mineral inclusion that is visible within the glass (Supplementary Fig. S6a). The remaining two shards show a strong correlation with material identified by Nooren et al. (2009) and Nooren et al. (2017) amongst El Chichón samples in delta deposits to the north of this volcano in Mexico. Although Nooren et al. (2009: 109) describe their Unit E shards as sharp-edged, the geochemical similarity of this material with 84-ky-old Los Chicoyos tephra from Atitlán, Guatemala, led Post (2016) and Nooren et al. (2017) to conclude that this component represents older, reworked tephra rather than primary ashfall. A similar cryptotephra has been reported in sparse quantities from European terrestrial sediments dating to ca. $650 \mathrm{CE}$ and $400 \mathrm{CE}$ (Plunkett \& Pilcher 2018: DOM-3 and DOM-4 Group 1) and NEEM-201 1-S 1 ice dating to $536 \mathrm{CE}$ (Sigl et al. 2015: QUB-1859 shards 1, 10 and 11). Contrary to Loveluck et al. (2018), this material is very distinct from Icelandic tephra and bears no geochemical similarity to the shards reported from the Colle Gnifetti ice core from Switzerland. The geochemical homogeneity of the distal correlatives leads us to question the attribution to a Pleistocene eruption of Atitlán, if indeed the cryptotephras are from the same source, as we would expect greater evidence for weathering from an 84-Ky-old deposit. Furthermore, it seems unlikely that remobilized sediment from a tropical environment would 
be transported to northern Europe and Greenland. Considering the frequency of a similar tephra in Mexican sediments, a source within this broader region seems likely.

The sample partly captures a minor particle peak in mid-823 CE, but coarse particle concentrations are below average for this ice core section. Despite a lack of association with sulphur, the shards comprise sharp glass and, with the exception of the example containing a mineral inclusion, have yielded consistent analyses. We argue, therefore, that they derive from a primary ashfall of unknown origin, but possibly emanating in southern North/Central America.

\section{Discussion}

Our study of two continuous ca. 20-year sections of Greenland ice reveals that the tephra presence in Late Holocene ice is not constant. Although the low flux of optically identifiable volcanic particles reaching the ice cores may imply that isolating tephra in these records is rather haphazard, a correspondence between observed glass shards and elevated fine particle content demonstrates that these sparse occurrences are associated with pulses of non-seasonal dust reaching the ice. In contrast, coarse minerals in all of our samples demonstrate that particles in the size range of the tephra shards we report are regularly transported to Greenland, especially to the north-eastern site of Tunu, but they are not palpably correlated with elevated sulphur or tephra (Supplementary Fig. S11). We can conclude that although large particles are persistently present in the ice cores, tephra shards are not, nor are the shards associated with elevated levels of coarse material. We infer that the sparse tephras we record are unlikely to be indicative of dust storm events.

of the five cryptotephra samples described here, we can identify with certainty the provenance of only one. Fortuitously, the unique geochemical composition of Katla basaltic tephra enables us to attribute QUB-1974 with high confidence to this volcano. Büntgen et al. (2017) demonstrated that a Katla eruption triggered a glacial outburst that is dated by dendrochronology to $822 / 3 \mathrm{CE}$ and proposed that this event was responsible for a sulphate anomaly in Greenland ice cores at this time. Our tephra shard, coinciding precisely with the 822 CE sulphate and particle peaks in TUNU2013, unequivocally corroborates this correlation, and we conclude that this solitary particle represents primary ashfall. The coeval deposition of sulphur and glass implies simultaneous transport by tropospheric or stratospheric winds, rather than the subsequent remobilization of glacial flood deposits as described by Prospero et al. (2012).

QUB-1835 has produced heterogeneous results from a single shard, preventing firm attribution to any specific source. The disparity may signify glass alteration, and there is no associated rise in volcanogenic sulphur to signify a coeval eruption. The absence of a sulphur peak in the ice does not, however, exclude the possibility that the material derives from primary ashfall: Öraefajökull 1362 CE tephra was recorded in high concentration in the GRIP core in the ice of the same age but was not accompanied by a sulphate layer (Coulter et al. 2012). Perhaps more telling is the absence of similarly sized dust particles and other terrestrial content that one might expect to be remobilized with reworked tephra. The remaining three samples in this study are more robust in their geochemical characterization but nevertheless pose conundrums in terms of understanding their derivation. QUB-1872 and QUB-1873 both possibly originate from the North Pacific region but neither clearly corresponds with a known Late Holocene tephra. In both instances, the potential source region lies upwind of Greenland, and it is conceivable that the shards represent reworked material, the geochemistry of which might have been altered through weathering. However, the coincidence of elevated sulphur and the absence of increases in other coarse particles strengthens the likelihood that the shards derive from unidentified eruptions.

QUB-1880 comprises a larger number of shards whose origins are less clear; that the major element geochemical composition was reproducible from two shards suggests that the glass geochemistry is unaltered. We find that material with matching major element geochemistry was deposited in Greenland and continental Europe on multiple occasions in the centuries preceding $824 \mathrm{CE}$, although the concentrations of tephra associated with these events are generally very low. We note a possible correlative also with an outlying population reported amongst El Chichón tephra in Mexico, implying a possible origin in southern North America or Central America, an improbable source region of remobilized dust that could reach northern Greenland and Europe. We propose, therefore, that the multiple incidents of this glass type represent primary ashfall.

Despite the difficulties in determining the source of all but one of the glass shards we have analysed, we conclude-with varying degrees of confidence-that the material represents primary deposition. We find no certain evidence of physical or chemical alteration of glass, and the samples containing confirmed tephra are not associated with increases in similarly sized terrestrial particles that we might expect had sediment been remobilized in dust storms.

\section{Conclusion}

We have examined the occurrence of tephra in two Greenland ice cores spanning a period of about 20 years, 
and their relationship to volcanogenic sulphur, fine (2.5$9.5 \mu \mathrm{m})$ and coarse $(>10 \mu \mathrm{m})$ particulate matter. Like previous studies (Abbott \& Davies 2012; Coulter et al. 2012), we find that not all sulphur peaks are associated with tephra; this may be because of eruptions that produced little or no ash, or ash clouds not reaching the ice core localities due to meteorological conditions or the distance of the eruption from the polar region. Equally, tephras are not always associated with sulphur peaks, highlighting that not all volcanic eruptions emit aerosols in concentrations to impact climate.

Tephra was present in six (possibly seven) of our 43 samples in low concentrations, despite the relatively sizeable samples examined in this study. These findings demonstrate that tephra occurrence in the ice cores is not rare, but nor is it consistently present as a background input as similarly coarse particulates appear to be. Specifically, tephra seems to occur in association with episodic pulses of particulate matter, often with elevated sulphur levels. The association of a solitary tephra shard of Katla origin with a sulphur layer contemporary with the 822 CE eruption of that same volcano in nearby Iceland serves to emphasize the potential significance of even a single shard in the ice cores, providing its geochemical composition is reliably distinct and replicable. Affirming previous work (Jensen et al. 2014; Sun et al. 2014; McConnell et al. 2017; Dunbar et al. 2019), our study demonstrates that exactly co-registered measurements of distinctive volcanic aerosols (e.g., sulphur) and fine particle size distribution in combination with exceptionally good age control of polar ice cores remain the best diagnostic tracer for the presence of tephra within the icecore strata.

At least two of the tephras we have recorded may have an origin in the North Pacific region, essentially upwind of Greenland given the dominant westerlies. Although only single shards were analysed for each of these samples, in neither instance do we find evidence that the shards are weathered. Their association with slightly elevated sulphur levels favours their interpretation as primary deposits from as yet unidentified eruptions. The sample that yielded the largest number of analysable shards finds its closest geochemical match with recurrent tephras reported in both Mexico and mainland Europe; we argue that the geochemical homogeneity shown by these tephras implies unweathered, primary ashfall, and that the source likely lies in the region around Mexico.

It follows that low shard concentration should not negate the potential significance of tephra in the polar ice cores; unless there are unambiguous signs of physical or chemical weathering or exceptional levels of coarse terrestrial matter, a single shard can aid the identification of the source volcanic eruption. Nevertheless, sparse concentrations of tephra present major challenges in terms of ensuring robust geochemical characterization and the differentiation of potentially altered glass. Where possible, we have obtained multiple analyses on individual grains to gauge the reliability of the geochemical signature and to assess the possibility of glass hydration. We advocate the quantification of tephra-sized particles within ice core samples as a means of evaluating the likelihood of remobilized sediment deposition at the ice core localities. In the absence of firm evidence for the presence of reworked tephra, and considering the exceptional weather conditions needed to transport remobilized material to high-altitude polar locations, we propose that tephras encountered in Greenland ice cores potentially relate to primary ash fall, irrespective of low shard concentrations.

\section{Acknowledgements}

We thank the many persons involved in logistics, drill developments and drilling, and ice-core processing and analysis in the field and in our laboratories. We thank Monica Arienzo, Daniel Pasteris, Larry Layman, Rachael Rhodes and Olivia Maselli for laboratory assistance. We are very grateful to Beth "Bella" Bergeron for her valuable expertise and hard work drilling the TUNU2013 cores. Our field team received valuable assistance from CHM2 Hill Companies Ltd. and Ken Borek Air. The NEEM project is directed by the Centre for Ice and Climate at the Niels Bohr Institute, Copenhagen, and the US National Science Foundation Office of Polar Programs. Trace element analysis was conducted on QUB-1835 with the assistance of Nick Pearce, Aberystwyth University. We are grateful to two anonymous reviewers whose constructive comments have helped to improve the manuscript.

\section{Disclosure statement}

The authors report no conflict of interest.

\section{Funding}

The NEEM project is supported by funding agencies and institutions in Belgium (Fund for Scientific ResearchFrench-speaking Community and Research Foundation-Flanders), Canada (Natural Resources Canada/ Geological Survey of Canada), China (Chinese Academy of Sciences), Denmark (Agency for Science and Higher Education), France (Paul-Emile Victor French Polar Institute, French National Centre for Scientific Research/ National Institute for Earth Sciences and Astronomy, 
French Alternative Energies and Atomic Energy Commission and French National Research Agency), Germany (the Alfred Wegener Institute), Iceland (Rannis-The Icelandic Centre for Research), Japan (National Institute of Polar Research), Korea (Korean Polar Research Institute), The Netherlands (Dutch Research Council/Earth and Life Sciences Division), Sweden (Swedish Research Council), Switzerland (Swiss National Science Foundation), the United Kingdom (Natural Environment Research Centre) and the USA (US National Science Foundation, Office of Polar Programs). Collection and primary chemical analyses of the NEEM-2011-S1 and TUNU2013 cores was funded by the US National Science Foundation grants 0909541, 1023672 and 1204176 to JRM. MS has received funding from the European Research Council under the European Union's Horizon 2020 research and innovation programme (grant agreement no. 820047). UB received funding from the programme SustES-Adaptation Strategies for Sustainable Ecosystem Services and Food Security Under Adverse Environmental Conditions (CZ.02.1.0 1/0.0/0.0/16_019/0000797). Trace element analysis was partly funded by a Quaternary Research Fund award to GP from the Quaternary Research Association.

\section{References}

Abbott P.M. \& Davies S.M. 2012. Volcanism and the Greenland ice-cores: the tephra record. Earth-Science Reviews 115, 173-191, doi: 10.1016/j.earscirev.2012.09.001.

Barbante C., Kehrwald N.M., Marianelli P., Vinther B.M., Steffensen J.P., Cozzi G., Hammer C.U., Clausen H.B. \& Siggaard-Andersen M.L. 2013. Greenland ice core evidence of the 79 AD Vesuvius eruption. Climate of the Past 9 , 1221-1232, doi: 10.5194/cp-9-1221-2013.

Bory A.M., Biscaye P.E., Piotrowski A.M. \& Steffensen J.P. 2003. Regional variability of ice core dust composition and provenance in Greenland. Geochemistry, Geophysics, Geosystems 4, article no. 1107, doi: 10.1029/2003GC000627.

Bory A.M., Biscaye P.E., Svensson A. \& Grousset F.E. 2002. Seasonal variability in the origin of recent atmospheric mineral dust at NorthGRIP, Greenland. Earth and Planetary Science Letters 196, 123-134, doi: 10.1016/ S0012-821X(01)00609-4.

Bourne A.J., Abbott P.M., Albert P.G., Cook E., Pearce N.J., Ponomareva V., Svensson A. \& Davies S.M. 2016. Underestimated risks of recurrent long-range ash dispersal from northern Pacific Arc volcanoes. Scientific Reports 6, article no. 29837, doi: 10.1038/srep29837.

Büntgen U., Eggertsson Ó., Wacker L., Sigl M., Ljungqvist F.C., Di Cosmo N., Plunkett G., Krusic P.J., Newfield T.P., Esper J., Lane C., Reinig F. \& Oppenheimer C. 2017. Multiproxy dating of Iceland's major pre-settlement Katla eruption to 822-823 CE. Geology 45, 783-786, doi: 10.1130/ G39269.1.

Büntgen U., Myglan V.S., Charpentier Ljungqvist F., McCormick M., Di Cosmo N., Sigl M., Jungclaus J., Wagner S.,
Krusic P.J., Esper J., Kaplan J.O., de Vaan M.A.C., Luterbacher J., Wacker L., Tegel W. \& Kirdyanov A.V. 2016. Cooling and societal change during the Late Antique Little Ice Age from 536 to around 660 AD. Nature Geoscience 9, 231-236, doi: 10.1038/ngeo2652.

Bursik M., Sieh K. \& Meltzner A. 2014. Deposits of the most recent eruption in the Southern Mono Craters, California: description, interpretation and implications for regional marker tephras. Journal of Volcanology and Geothermal Research 275, 114-131, doi: doi.org/10.1016/j. jvolgeores.2014.02.015.

Cao L.Q., Arculus R.J. \& McKelvey B.C. 1995. Geochemistry and petrology of volcanic ashes recovered from Sites 881 through 884: a temporal record of Kamchatka and Kurile volcanism. Proceedings of the Ocean Drilling Program, Scientific Results 145, 345-381.

Coulter S.E., Pilcher J.R., Plunkett G., Baillie M.G.L., Hall V.A., Steffensen J.P., Vinther B.M., Clausen H.B. \& Johnsen S.J. 2012. Holocene tephras highlight complexity of volcanic signals in Greenland ice cores. Journal of Geophysical Research-Atmospheres 117, D21303, doi: 10.1029/2012JD017698.

Dunbar N.W., Iverson N.A., Van Eaton A.R., Sigl M., Alloway B.V., Kurbatov A.V., Mastin L.G., McConnell J.R. \& Wilson C.J.N. 2017. New Zealand supereruption provides time marker for the Last Glacial Maximum in Antarctica. Scientific Reports 7, article no. 12238, doi: 10.1038/ s41598-017-11758-0.

Esper J., Schneider L., Krusic P.J., Luterbacher J., Büntgen U., Timonen M., Sirocko F. \& Zorita E. 2013. European summer temperature response to annually dated volcanic eruptions over the past nine centuries. Bulletin of Volcanology 75, article no. 736, doi: 10.1007/s00445-013-0736-z.

Flanner M.G., Gardner A.S., Eckhardt S., Stohl A. \& Perket J. 2014. Aerosol radiative forcing from the 2010 Eyjafjallajökull volcanic eruptions. Journal of Geophysical ResearchAtmospheres 119, 9481-9491, doi: 10.1002/2014JD021977.

Froggatt P.C. 1992. Standardization of the chemical analysis of tephra deposits. Report of the ICCT working group. Quaternary International 13, 93-96, doi: 10.1016/1040-6182(92)90014-S.

Hadley D., Hufford G.L. \& Simpson J.J. 2004. Resuspension of relic volcanic ash and dust from Katmai: still an aviation hazard. Weather and Forecasting 19, 829-840, doi: 10.1175/1520-0434(2004)019<0829:RORVAA>2.0.CO;2.

Hammer C.U., Clausen H.B. \& Dansgaard W. 1980. Greenland ice sheet evidence of post-glacial volcanism and its climatic impact. Nature 288, 230-235, doi: 10.1038/288230a0.

Hayward C. 2012. High spatial resolution electron probe microanalysis of tephras and melt inclusions without beam-induced chemical modification. The Holocene 22, 119-125, doi: 10.1177/0959683611409777.

Hildreth W. \& Fierstein J. 2012. The Novarupta-Katmai eruption of 1912-largest eruption of the twentieth century: centennial perspectives. Professional Paper 1791. Reston, VA: US Geological Survey.

Hunt J.B. \& Hill P.G. 1993. Tephra geochemistry: a discussion of some persistent analytical problems. The Holocene 3, 271-278, doi: 10.1177/095968369300300310. 
Iverson N.A., Kalteyer D., Dunbar N.W., Kurbatov A. \& Yates M. 2017. Advancements and best practices for analysis and correlation of tephra and cryptotephra in ice. Quaternary Geochronology 40, 45-55, doi: 10.1016/j. quageo.2016.09.008.

Jensen B.J.L., Pyne-O'Donnell S., Plunkett G., Froese D.G., Hughes P.D.M., Sigl M., McConnell J.R., Amesbury M.J., Blackwell P.G., van den Bogaard C., Buck C.E., Charman D.J., Clague J.J., Hall V.A., Koch J., Mackay H., Mallon G., McColl L. \& Pilcher J.R. 2014. Transatlantic distribution of the Alaskan White River Ash. Geology 42, 875-878, doi: 10.1130/G35945.1.

Loveluck C.P., McCormick M., Spaulding N.E., Clifford H., Handley M.J., Hartman L., Hoffmann H., Korotkikh E.V., Kurbatov A.V., More A.F. \& Sneed S.B. 2018. Alpine icecore evidence for the transformation of the European monetary system, AD 640-670. Antiquity 92, 1571-1585, doi: 10.15184/aqy.2018.110.

Lowe D.J. 2011. Tephrochronology and its application: a review. Quaternary Geochronology 6, 107-153, doi: 10.1016/j.quageo.2010.08.003.

Lucchi F., Tranne C.A., De Astis G., Keller J., Losito R. \& Morche W. 2008. Stratigraphy and significance of brown tuffs on the Aeolian Islands (southern Italy). Journal of Volcanology and Geothermal Research 177, 49-70, doi: 10.1016/j. jvolgeores.2007.11.006.

Lupker M., Aciego S.M., Bourdon B., Schwander J. \& Stocke, T.F. 2010. Isotopic tracing ( $\mathrm{Sr}, \mathrm{Nd}, \mathrm{U}$ and $\mathrm{Hf}$ ) of continental and marine aerosols in an 18th century section of the Dye-3 ice core (Greenland). Earth and Planetary Science Letters 295, 277-286, doi: 10.1016/j.epsl.2010.04.010.

Maselli O.J., Chellman N.J., Grieman M., Layman L., McConnell J.R., Pasteris D., Rhodes R.H., Saltzman E. \& Sigl M. 2017. Sea ice and pollution-modulated changes in Greenland ice core methanesulfonate and bromine. Climate of the Past 13, 39-59, doi: 10.5194/cp-13-39-2017.

McConnell J.R., Burke A., Dunbar N.W., Kohler P., Thomas J.L., Arienzo M.M., Chellman N.J., Maselli O.J., Sigl M., Adkins J.F., Baggenstos D., Burkhart J.F., Brook E.J., Buizert C., Cole-Dai J., Fudge T.J., Knorr G., Graf H.F., Grieman M.M., Iverson N., McGwire K.C., Mulvaney R., Paris G., Rhodes R.H., Saltzman E.S., Severinghaus J.P., Steffensen J.P., Taylor K.C. \& Winckler G. 2017. Synchronous volcanic eruptions and abrupt climate change similar to 17.7 ka plausibly linked by stratospheric ozone depletion. Proceedings of the National Academy of Sciences of the United States of America 114, 10035-10040, doi: 10.1073/ pnas. 1705595114.

Miyake F., Nagaya K., Masuda K. \& Nakamura T. 2012. A signature of cosmic-ray increase in $\mathrm{AD}$ 774-775 from tree rings in Japan. Nature 486, 240-242, doi: 10.1038/ naturel1123.

Nooren C.A.M., Hoek W.Z., Tebbens L.A. \& Martín Del Pozzo A.L. 2009. Tephrochronological evidence for the late Holocene eruption history of El Chichón Volcano, Mexico. Geofísica Internacional 48, 97-112.

Nooren K., Hoek W.Z., Van Der Plicht H., Sigl M., van Bergen M.J., Galop D., Torrescano-Valle N., Islebe G., Huizinga A., Winkels T. \& Middelkoop H. 2017. Explosive eruption of
El Chichón volcano (Mexico) disrupted 6th century Maya civilization and contributed to global cooling. Geology 45, 175-178, doi: 10.1130/G38739.1.

Palais J.M., Germani M.S. \& Zielinski G.A. 1992. Inter-hemispheric transport of volcanic ash from a 1259 AD volcanic eruption to the Greenland and Antarctic ice sheets. Geophysical Research Letters 19, 801-804, doi: 10.1029/92GL00240.

Plunkett G. \& Pilcher J.R. 2018. Defining the potential sources region of volcanic ash in northwest Europe during the Mid- to Late Holocene. Earth-Science Reviews 179, 20-37, doi: 10.1016/j.earscirev.2018.02.006.

Ponomareva V., Portnyagin M., Pendea I.F., Zelenin E., Bourgeois J., Pinegina T. \& Kozhurin A. 2017. A full Holocene tephrochronology for the Kamchatsky Peninsula region: applications from Kamchatka to North America. Quaternary Science Reviews 168, 101-122, doi: 10.1016/j. quascirev.2017.04.031.

Ponomareva V., Portnyagin M., Pevzner M., Blaauw M., Kyle P. \& Derkachev A. 2015. Tephra from andesitic Shiveluch volcano, Kamchatka, NW Pacific: chronology of explosive eruptions and geochemical fingerprinting of volcanic glass. International Journal of Earth Sciences 104, 1459-1482, doi: 10.1007/s00531-015-1156-4.

Post J. 2016. Reconstructing the eruption history of El Chichón volcano from river terraces (Chiapas, Mexico). Master's thesis, Dept. of Earth Science, University of Utrecht.

Prospero J.M., Bullard J.E. \& Hodgkins R. 2012. High-latitude dust over the North Atlantic: inputs from Icelandic proglacial dust storms. Science 335, 1078-1082, doi: 10.1126/science.1217447.

Robock A. 2000. Volcanic eruptions and climate. Reviews of Geophysics 38, 191-219, doi: 10.1029/1998RG000054.

Ruth U., Wagenbach D., Steffensen J.P. \& Bigler M. 2003. Continuous record of microparticle concentration and size distribution in the central Greenland NGRIP ice core during the last glacial period. Journal of Geophysical Research-Atmospheres 108, article no. 4098, doi: 10.1029/2002JD002376.

Siebert L., Simkin T. \& Kimberly P. 2011 . Volcanoes of the world. 3rd edn. Berkeley: University of California Press.

Sigl M., McConnell J.R., Layman L., Maselli O., McGwire K., Pasteris D., Dahl-Jensen D., Steffensen J.P., Vinther B., Edwards R. \& Mulvaney R. 2013. A new bipolar ice core record of volcanism from WAIS Divide and NEEM and implications for climate forcing of the last 2000 years. Journal of Geophysical Research-Atmospheres 118, 11511169 , doi: 10.1038/nature 14565.

Sigl M., Winstrup M., McConnell J.R., Welten K.C., Plunkett G., Ludlow F., Büntgen U., Caffee M., Chellman N., Dahl-Jensen D., Fischer H., Kipfstuhl S., Kostick C., Maselli O.J., Mekhaldi F., Mulvaney R., Muscheler R., Pasteris D.R., Pilcher J.R., Salzer M., Schüpbach S., Steffensen J.P., Vinther B.M. \& Woodruff T.E. 2015. Timing and climate forcing of volcanic eruptions for the past 2,500 years. Nature 523, 543-549, doi: 10.1038/nature 14565.

Steen-Larsen H.C., Masson-Delmotte V., Sjolte J., Johnsen S.J., Vinther B.M., Bréon F.M., Clausen H.B., Dahl-Jensen D., Falourd S., Fettweis X. \& Gallée H. 2011 . Understanding the climatic signal in the water stable isotope records from the NEEM shallow firn/ice cores in northwest Greenland. 
Journal of Geophysical Research-Atmospheres 116, D6, doi: 10.1029/2010JD014311.

Stoffel M., Khodri M., Corona C., Guillet S., Poulain V., Bekki S., Guiot J., Luckman B.H., Oppenheimer C., Lebas N. \& Beniston M. 2015. Estimates of volcanic-induced cooling in the Northern Hemisphere over the past 1,500 years. Nature Geoscience 8, 784-788, doi: 10.1038/ngeo2526.

Sun C.Q., Plunkett G., Liu J.Q., Zhao H.L., Sigl M., McConnell J.R., Pilcher J.R., Vinther B., Steffensen J.P. \& Hall V. 2014. Ash from Changbaishan Millennium eruption recorded in Greenland ice: implications for determining the eruption's timing and impact. Geophysical Research Letters 41, 694-701, doi: 10.1002/2013GL058642.

Tanaka T.Y. \& Chiba M. 2006. A numerical study of the contributions of dust source regions to the global dust budget. Global and Planetary Change 52, 88-104, doi: 10.1016/j. gloplacha.2006.02.002.
Toohey M., Krüger K., Schmidt H., Timmreck C., Sigl M., Stoffel M. \& Wilson R. 2019. Disproportionately strong climate forcing from extratropical explosive volcanic eruptions. Nature Geoscience 12, 100-107, doi: 10.1038/ s41561-018-0286-2.

Zielinski G.A., Dibb J.E., Yang Q., Mayewski P.A., Whitlow S., Twickler M.S. \& Germani M.S. 1997. Assessment of the record of the 1982 El Chichón eruption as preserved in Greenland snow. Journal of Geophysical Research-Atmospheres 102, D25, 30031-30045, doi: 10.1029/97JD01574.

Zielinski G.A., Mayewski P.A., Meeker L.D., Whitlow S., Twickler M.S., Morrison M., Meese D.A., Gow A.J. \& Alley B. 1994. Record of volcanism since 7000 B.C. from GISP2 Greenland ice core and implications for the volcano-climate system. Science 264, 948-952, doi: 10.1126/ science.264.5161.948. 